\title{
SIEMPRE OLVIDO EL PARAGUAS CUANDO TENGO SED ${ }^{1}$
}

\author{
Marcela Terra ${ }^{2}$
}

OBRA POÉTICA EN UN ACTO 3

Personajes

Mujer 1 Mujer 2 Mujer 3

Niña 1 Niña 2 Niña 3

Ifigenia Cassandra Ofelia

Marino Profesor Alumna

Presentador Público 1 Público 2

${ }^{1}$ Fecha de recepción: 17/10/2019.

Fecha de aceptación: 29/11/2019.

${ }^{2}$ La autora y directora de teatro Marcela Terra es Licenciada en Artes, dramaturga y directora de teatro, tiene una experiencia de más de veinte años en el mundo de la dirección, la dramaturgia y la escritura creativa. Como autora de teatro ha escrito: Chejovianas, 1973, El Frío, Los Girasoles de Van Gogh, Bruto, el poder o la virtud, La Espera, Siempre Olvido el paraguas cuando tengo sed, Simone, La Carne, Entre las Olas. Virginia Woolf, Palabra y Vida, El Puente, Desterradas y Ofelia. Como directora, ha estado al frente de la mayoría de los montajes que ha escrito, así como también de los espectáculos: Ícaro de A. Lladó, El Amateur, de M. Dayub, A Puerta cerrada, de J. P. Sartre, El Mercader de Venecia, de W. Shakespeare, Hedda Gabler, de H. Ibsen, El Tony Chico, de L. A. Heiremans, El Marino que perdió la gracia del mar, de Yukio Mishima, Los Encantos de la Culpa, de P. Calderón de la Barca, entre otros. Además de dedicar buena parte de su carrera a la docencia y la formación continuada, ha recibido los premios Eugenio Guzmán al Mejor Director por Crónica de una muerte anunciada (2001) y el del Fondo Nacional de las Artes de Chile, Fondart, por Reflexiones sobre una vida absurda o Te necesito tanto, padre (2001). También ha publicado en Arola Editors cuatro de sus obras: La Espera, Simone, Entre las Olas y Desterradas y en la Editorial Edual su pieza Los Girasoles de Van Gogh; $\bowtie$ marcelaterr@hotmail.com.

${ }^{3}$ Barcelona, Versión 2016. 


\section{ESCENA 1}

\section{El comienzo del viaje}

Elementos para un ritual. En la escena agua, arena, relojes de arena, relojes de agua. Barcos de papel, barcos de juguete, barcos en miniatura. Fotos de mascarones de proa, mascarones de proa en miniatura, maletas y paraguas. Una ventana cuelga a la izquierda. En el suelo tierra azul, piedras azules. La luz: reflejos de faro, girando. Al fondo rocas y un faro.

Se escucha el sonido del mar que se mezcla con un piano. La Pavane de Ma Mere l'Oye de Maurice Ravel. Entra una mujer, viste ropas de finales del siglo XIX. Camina recorriendo las líneas de un mapa en el suelo, una rosa de los vientos. Cruza la escena. Se detiene en una esquina del escenario. Su postura es la de un mascaron de proa.

-MUJER 3: Estoy aquí, estoy despacio...día, mes, año...una fecha... ¿Es el día, mes, año?... No lo sé. Escucho el mar. El mar viene a mí, como una ráfaga. (Se escucha el mar) Una ráfaga que choca contra las rocas. Soy esa agua salada que choca insistentemente contra las rocas. Soy gotas que se arrastran por la piedra y soy sal, sal que carcome la piedra y soy, soy, soy, pero no fui, antes fui silencio, silencio que desde el cielo daba señales a las nubes para bajar...

Estoy atrapada, no soy agua, soy roca, roca y necesito partir... 
Partir, partir, quiero partir ahora...Estar al otro lado del mundo, el mundo...un mundo en línea recta. En línea recta hasta caer del mundo, al espacio, al vacío. (Ríe.) Pero, no. (Pensando.) No caería. Si sigo en línea recta...si pudiera simplemente intentar seguir y seguir hasta el infinito...un infinito en línea recta...llegaría hasta aquí... Llegaría a este mismo lugar. El infinito sería este. Quiero ser infinito. Una mujer en el infinito. En línea recta para encontrar el infinito... aquí...

Las mujeres que escuchan replican, irónicas, riendo.

-MUJER 1: Es imposible.

-MUJER 2: Una mujer no puede hacerlo.

-MUJER 1: Es una locura.

-MUJER 2: No puede viajar sola.

-MUJER 1: Necesita un protector.

-MUJER 2: Si, alguien que cuide de ella.

-MUJER 1: Que la proteja.

-MUJER 2: Necesita equipaje.

-MUJER 1: Y alguien que lo lleve.

-MUJER 2: Baúles y baúles de equipaje.

-MUJER 1: Es mucho tiempo...

-MUJER 2: No sabe inglés.

-MUJER 1: Claro, no sabe otros idiomas. 
-MUJER 2: No, no puede ir sola.

-MUJER 1: Es imposible.

-MUJER 2: Tiene que hacerlo un hombre.

-MUJER 1: Un hombre sí.

-MUJER 2: Solamente un hombre puede hacerlo.

-MUJER 1: Sí. Una mujer de ningún modo.

-MUJER 2: Mucho equipaje.

-MUJER 1: Una mujer necesita mucho equipaje.

-MUJER 2: Imposible hacer trasbordos rápidos.

-MUJER 1: Tiene que llevar un acompañante.

-MUJER 2: Sí, un acompañante...

-MUJER 1: ...y mucho equipaje...

\section{MUJER 3 Interrumpe gritando.}

-MUJER 3: ¡Envíen a un hombre!... que yo haré el mismo viaje... (Se va, pero vuelve.) ¡Y llegaré antes! (Da la espalda y vuelve.) Y daré la vuelta al mundo...la vuelta al mundo... (Gritando.) ¡Con un sólo vestido!

Las dos mujeres la miran con incredulidad y salen riendo. MUJER 3 coge una bolsa de viaje en miniatura y va poniendo dentro los objetos que va mencionando. Todos los objetos son en miniatura menos el vestido. 
-MUJER 3: Dos gorros de viaje, un par de zapatillas, cepillo, peine, pinzas de pelo, cintas, pañuelos y ropa interior. Una polvera, una bata. El abrigo...no, el abrigo lo llevo puesto. Una petaca para el agua y un vaso. Tintero, plumas y lápices. Agujas, dedal e hilo. Una pequeña tijera. Ah! Crema hidratante, guantes, una bufanda. Y otro vestido... (El vestido es de tamaño real. Intenta ponerlo en el bolso pero no le cabe.) No, no cabe, no cabe... jun solo vestido!... Sí, iré con un solo vestido... (Lo lanza lejos, el vestido desaparece volando.)

MUJER 3 se ata el pequeño bolso a la muñeca. Está lista para partir. Se escucha un piano. El inicio de Les entretiens de Ma Mere l'Oye de Maurice Ravel. MUJER 1 y MUJER 2 entran por distintos lados del escenario cruzan la escena caminando como si recorrieran las líneas de un mapa en el suelo, la rosa de los vientos. MUJER 3 sale, MUJER 1 se apoya en la ventana.

\section{ESCENA 2}

\section{La Mujer en la ventana}

MUJER 1 apoyada en la ventana, de espaldas al público como el cuadro de Dalí. MUJER 2 la observa de lejos. Habla. 
-MUJER 2: La mujer aguarda en la ventana. Se apoya sobre sus codos y el peso de la espalda, la piel, el pelo, caen sobre el marco de la ventana. La mujer se apoya y deja vagar sus pensamientos. Cada tarde se apoya, mirando el infinito. Mirando el mar. El mar le trae recuerdos. El mar le trae aromas, de aquel que se fue, de aquel que no vuelve. La mujer suspira. (MUJER 1 suspira)

La mujer suspira porque sabe que no volverá. La mujer suspira y en el suspiro lo invoca. Levanta la mano y mueve los dedos en el aire. Es el barco el que dibuja a lo lejos. Es la sombra de un barco. Y lo imagina venir. Espera hasta que anochece. Fabula que vuelve, que está aquí. Y para no verse, para no ver su soledad, se cubre el rostro con un pañuelo blanco. Se lo amarra detrás de la cabeza. Abre y cierra la boca blanca como un pez ahogado de aire. Y desnuda su cuerpo frente al espejo a la espera de que su imagen sea una presencia capaz de tocarla, de abrazarla. Como si su imagen fuera otro, fuera él. Ciega avanza hasta el espejo y se palpa suavemente con los dedos, pero, no hay calor ninguno que venga a tocarle las manos, el espejo frío no es más que una imagen de mujer con la cara tapada. Acerca sus labios a los labios del espejo. Esta vez sí, el pacto está a punto de cumplirse, pero el paño húmedo sobre el rostro le impide besarse. Tiembla con las manos crispadas y la piel doliente. En un arranque de impaciencia hunde los dedos entre sus muslos, en medio de un grito silencioso se arranca el paño de la cabeza y se mira con ojos vacíos. Se acerca a la ventana. Mira al horizonte. La luz de la luna sobre el mar trae un camino de reflejos hasta su cama. Los reflejos de un barco a la distancia. Se apoya otra vez en el marco de la ventana, mirando el mar... 


\section{ESCENA 3}

\section{El viento en el mar}

Sonidos de ráfagas de viento. Contraluz. Apenas se distinguen las siluetas de las mujeres que cruzan de un lado a otro la escena. Como si ellas fueran el viento que sopla.

-MUJER 1: Escucha, es el viento el que sopla

-MUJER 3: Se arrastra entre los pinos

Encima del mar

-MUJER 2: ¡Deja!, no quiero que me lleve

-MUJER 1: Es el viento el que se arrastra

Con vivos y con muertos

-MUJER 3: Cómo si quisiera vengar la tierra

-MUJER 2: Como si quisiera romperla

-MUJER 1: Déjame seguir aquí

Atada a tu cintura

Mientras el vendaval arrasa la tierra

-MUJER 3: Es el viento el que sopla fuerte

-MUJER 2: El que quiere alejarnos

El que te lleva

-MUJER 1: Abrázame que aunque me busque no me encontrará

-MUJER 3: Y seguiremos así 
(Sonidos de ráfagas de viento.)

-MUJER 2: Atados en la sombra, amor mío.

-MUJER 3: Atados en la sombra, amor mío.

-MUJER 2: Atados en la sombra, amor mío.

(El último texto se repite cientos de veces hasta convertirse en una ráfaga que las envuelve.)

\section{ESCENA 4}

\section{La mujer de la ventana recuerda a su amado}

MUJER 2 Y MUJER 3 Desaparecen en la oscuridad, entre el murmullo de sus voces repitiendo el poema y el sonido del viento y el mar. MUJER 1 dice el texto como una declaración de amor a su amado al que mira dormir. Durante el texto que comienza en silencio, se va apoderando sutilmente del espacio, el sonido del mar.

-MUJER 1: Cuando la noche cae

Se escucha respirar la tierra

El viento en calma acompaña el vaivén de las olas

Y tu cuerpo dormido me abraza

Sin saber sin sentirlo apenas

Nos dejamos naufragar después del amor 
Arrojados a la playa como peces

Soñando el agua

Te busqué y me buscabas

Entre el mar oscuro

Las hojas el viento

Era el mar el que gritaba tu nombre

Con sonidos lejanos ajenos

El que me hablaba y no sabía decir

Era el mar el que decía mi nombre

El que interrumpía tu sueño

El que te hablaba de mí

Fue nuestro el atardecer de tu cuerpo lanzado en la arena

Fue nuestra la noche que nos devolvió la vida

Ahora estas ahí dormido como si estuvieras muerto

Tus piernas enlazan las mías

Los pies se pierden no sé cuál es tuyo o mío

Y el brazo que descansa en mi cuello

Es tu garganta y mi boca

Nuestros latidos al unísono

Arrastran el mar que lame la arena

Y espero que no llegue el día

Que no llegue el día y que tu pie se deshaga del mío 
Que tu boca y mi boca sean dos palabras distintas

Y los rayos del sol dibujen sombras diferentes

Solo queda esperar a que llegue la noche

Para buscarnos ciegos para lamernos

Para enroscarme a tu cintura y dormir

Dormir como si hubiéramos muerto

\section{ESCENA 5}

\section{El Prostíbulo}

La declaración de amor se rompe con una música de Charlestón. Mujer 2 y Mujer 3 entran riendo, vestidas de los años 1920-30. Traen en las manos elementos para vestir a la Mujer 1. La escena se convierte en un cabaret del puerto de Nueva York.

-MUJER 3: ¡Ya llegan! los barcos llegan a puerto

-MUJER 2: Vienen desde África a Nueva York

-MUJER 3: Con sus hombres duros de sal

Se acercan raudos a la tierra

-MUJER 2: Guiados por mascarones de popa

Abriendo el camino

-MUJER 1: Mujeres de tronco de madera húmedas de mar 
-MUJER 3: El solitario mascarón cruza el océano

Cubierto de algas

-MUJER 2: Del desierto al oro

De la sequedad a la fortuna

-MUJER 1: Ella gastada de sal

-MUJER 3: Moles enormes de cemento

Recortan el cielo de Nueva York

-MUJER 2: En el horizonte solo las oficinas de Wall Street

-MUJER 1: La moneda sube y baja

Sube y baja

Y siempre cae en el bolsillo del banquero

-MUJER 3: Esa moneda que jamás toca las manos de los niños pobres

-MUJER 2: Ni de las mujeres

-MUJER 1: Ni de los obreros

-MUJER 2: Ni los explotados

-MUJER 3: El mascarón sabe y calla

-MUJER 1: El mascarón mira y llora lágrimas marinas

-MUJER 3: Sabe que los hombres solo miran nuestro sexo

-MUJER 2: Y los banqueros el dinero

-MUJER 3: Y los políticos el poder

-MUJER 2: Y los curas la gloria

-MUJER 1: La gloria de Dios 
- MUJER 1, 2, 3: Amén

-MUJER 3: El mascarón choca una y otra vez

Golpeándose contra el muelle

-MUJER 2: Sabe que Dios no baila con nosotras

-MUJER 1: Ni Dios ni el Papa

-MUJER 3: Ni el político

-MUJER 2: Ni el banquero

-MUJER 3: Solo este mascarón que verá su fin

En un puerto de Nueva York

MUJER 3 sale.

-MUJER 1: Los marineros se abrazan al mascarón.

-MUJER 2: Porque se ven naufragar.

-MUJER 1: Son los marineros los que han visto

El pánico en el fondo del mar.

-MUJER 2: Son marineros los que dejan

Mujeres apoyadas en las ventanas mirando el mar.

-MUJER 1: Hipnotizadas con el horizonte y la promesa que volverán.

-MUJER 2: Son agua. Sueños de agua. Explosiones de agua y sequedad.

-MUJER 1: Marinos que saben el espanto de la aridez.

De estar anclados en puertos sin alas. 
-MUJER 2: ¿Se puede ser más firme que el mar? ¡Blanco!

-MUJER 1: Blanco sobre cubierta.

-MUJER 2: Blanco.

-MUJER 1: Brújula.

-MUJER 2: Bitácora.

MUJER 1 y MUJER 2 hablan de la historia del Marinero. Mientras relatan el encuentro del Marinero con la mujer cabeza de pez, MUJER 3 entra vestida de marinero y realiza acciones de marinos en la cubierta de un barco.

-MUJER 1: Un marinero un día encontró a una mujer.

-MUJER 2: ¿Muerta?

-MUJER 1: A una mujer con cabeza de pez.

-MUJER 2: ¿Muerta?

-MUJER 1: No podía hablar, no decía nada.

-MUJER 2: Estaba muerta.

-MUJER 1: Hacia un ruido extraño, de pez ahogándose en el aire. (Hace el ruido).

-MUJER 2: ¿Era una sirena?

-MUJER 1: Todo lo contrario de una sirena.

-MUJER 2: $¿ \ldots ?$

-MUJER 1: El marino la oía ahogarse y moverse. Tenía unas piernas hermosas y alcanzaban a dibujarse sus pechos. 
-MUJER 2: ¿Cómo es lo contrario de una sirena?

-MUJER 1: El Marino estaba excitado por su belleza...

-MUJER 2: ¿Era una mujer?

-MUJER 1: ... Tanto que no era capaz de mirar su rostro. El marino se bajó los pantalones y la penetró...

-MUJER 2: Ella no quería...

-MUJER 1: No, pero la mujer cabeza de pez no podía decir nada, no hablaba. Aunque su corazón le gritaba ¡no me toques!, ¡déjame en paz!, ¡no me toques!, devuélveme al mar...necesito ir al mar...

-MUJER 2: No hablaba...el mar...

-MUJER 1: ...pero el marino no paró hasta que acabó. La miró con sus ojos grises de no ver nada. No escuchó su súplica. Los ojos de ella se fueron quedando fijos, se fueron poniendo opacos. Lloraba pero no tenía lágrimas...

-MUJER 2: Era un pez.

-MUJER 1: El Marinero de pronto la vio y tuvo miedo. Miedo de esa aparición tendida en la arena e intentó correr, pero algo le impedía moverse. En su cabeza escuchaba la voz de ella: un canto de muerte. El Marinero la empujó al mar... en el momento que lo hacía una ola como una cuna la recibió y se la llevó al fondo. Desapareció.

-MUJER 2: ¿Y el marinero?

-MUJER 1: Desapareció.

-MUJER 2: ¿En el mar?

-MUJER 1: No se sabe, en el mar, en el faro, entre las rocas... 
(El marinero desaparece.)

-MUJER 2: No quiero ser marinero

-MUJER 1: ¿Entonces?

-MUJER 2: No sé. Otra cosa. Una cuerda...le damos cuerda, mucha cuerda para que el barco pueda partir...que aleje a los marineros de la playa.

-MUJER 1: Que no exista más combate... No me gustan sus uniformes... y sus cañones...

-MUJER 2: Prefiero un barco vacío...Un barco encallado, un barco naufragado...un barco de papel...

\section{ESCENA 7}

\section{El verano y el mar}

-MUJER 3: De niña, viajaba en la parte de atrás del coche, la vista fija en el parabrisas para ser la primera en ver el mar...la última curva, la última loma del camino y ¡zas! entre la copas de los pinos a lo lejos el mar... "el inmenso mare”... Abría la puerta del coche y entraba corriendo en casa tras la maleta, que hurgaba con desespero, y mi madre gritando: ¡iespera, ya va!!! Me ponía el traje de baño y bajaba corriendo hasta la playa. Con los pies en el agua permanecía absorta, como si fuera la única frente al mar. La única que lo ve, la única que lo escucha, la única a la que el Mar le habla... Hablábamos él y yo. Un dialogo íntimo, un diálogo de amantes, un juego erótico de entrar y salir, de desafiar a las olas, de arrastrarme por la espuma y la arena y otra vez el salto, el pelo mojado y con furia desafiar 
esa cortina, cruzarla era el juego, levantarte era el tuyo, como quien se levanta las faldas. Y mostrar una transparencia líquida, casi inocente, de mar madre, de mar amante y yo niña. No había miedo, el miedo no existía, en tu violencia me protegías y en tu furia me lanzabas fuera. No existía el miedo, en ti todo era dulce-sal. En ti, año tras año el misterio de los pies en el agua y tu lengua marina susurrando destinos. El tuyo y el mío. El momento de partir... Entonces no sabía o no quería saber que el tiempo corre de prisa y no sabe de destinos... De destinos jurados frente al mar. Y llega pronto la vejez del agua sucia, los peces muertos, las sirenas ahogadas. El cansancio de las olas. El frío. El miedo y el frío. Frente a ti ya no rompo las olas, frente a ti, atrapado y furioso contra el mundo: iquiero salir! Frente a ti, atrapada en mi cuerpo y furiosa frente al mundo: ¡quiero salir! Ya no bajo corriendo hasta la orilla, ya no llevo el bañador puesto, ni entro los pies en el agua. Te miro desde la orilla, me ves y te veo, nos sentimos. Melancolía es la palabra... Melancolía de estar viéndonos atrapados en el silencio de un solo destino: hacia la soledad y hacia la muerte... Creo que solo sé historias tristes...

\section{ESCENA 8}

\section{Las tres hermanas. De la niñez a la Adolescencia. El rito y la tragedia}

Suena el Passepied de la Suite Bergamasque de Claude Debussy. Las niñas pasan caminando en distintos ritmos, siguiendo las líneas de un mapa en el suelo, la Rosa de los Vientos. Entran arrastrando una maleta y luego cientos de caracolas que dejan en el suelo. 
La NIÑA 1 corriendo con una caracola de mar grande, se escuchan los sonidos de esta caracola. Entra la NIÑA 2 corriendo, su caracola es más grande que la primera, el ruido del mar suena aún más fuerte. Entra la NIÑA 3 con una caracola inmensa, apenas se la puede, se arrastra llevándola, el mar suena aún más fuerte. Las ponen en el suelo como imitando una ola. NIÑA 1 escucha la primera, la segunda, la tercera.

-NIÑA 1: Las maletas de los viajeros están llenas de caracolas... Las caracolas están llenas de sonidos, de palabras...de palabras tristes, porque los viajeros se llevan las caracolas lejos del mar...para olvidarlas en los estantes, entre los libros, cada día un sonido nuevo...una nueva queja: quiero volver al mar, quiero volver al mar...

-NIÑA 2: Maletas a la orilla de la playa, maletas en la puerta de casa y la madre en el sillón soñando con los hijos que se van...

-NIÑA 3: Pero yo no quiero partir...

-NIÑA 2: Siempre hay que partir...

-NIÑA 3: Yo no quiero partir...

-NIÑA 1: Tiene miedo...

-NIÑA 2: Sí, Tiene miedo, tiene miedo...

-NIÑA 1: Tenemos que irnos lejos, lejos de este reino, a otros reinos...otras tierras

-NIÑA 2: Todas vamos a buscar un destino...

-NIÑA 1: Y ser Reinas al otro lado del mar... 
Pequeña canción infantil. Corren, juegan mientras van cantando Vuelven los acordes del Passepied. NIÑA 3 interrumpe el juego.

-NIÑA 3: Inventemos un destino

-NIÑA 1: Entre ser y no ser

-NIÑA 2: Ser de agua o de piel

-NIÑA 3: Ser víctima o asesino

-NIÑA 1: Juego, juego, juego a quién le toca a ser...

-NIÑA 2: ¡Nora!

-NIÑA 1: ¡Fedra!

-NIÑA 3: ¡Elena!

-NIÑA 1: ¡Ofelia!

-NIÑA 2: ¡Hedda!

-NIÑA 3: ¡Simone!

-NIÑA 1: ¡Yerma!

-NIÑA 2: Un, dos, tres...cape nane nu, ene tene tú A ti Ifigenia

-NIÑA 3: No yo no no me gusta yo no quiero ser viento...

-NIÑA 1: Entonces... Ofelia...Cassandra o Yerma...

-NIÑA 3: No quiero ser agua No quiero estar seca

-NIÑA 2: Yo no quiero saber

-NIÑA 1: ¿Y Yerma?, ¿quién será Yerma? 
-NIÑA 3: Nadie quiere ser yerma la de los pechos secos la de los labios fríos la del dolor en el vientre....

-NIÑA 1: Está bien nadie será Yerma...Preparémonos para la representación... tu eres, tú eres...Ifigenia. (Indicando a la NIÑA 1 . La niña se enfada.) Y tu Ofelia. (Indicando a la NIÑA 3 .La niña se enfada.) A mí me agrada... yo... yo seré, yo seré ...Cassandra ...

(Buscan algún elemento de vestuario en la maleta. Una luz manual, de linterna y lo hacen como un teatro familiar, teatro de títeres.)

-NIÑA 1: Tú... (Indicando a la NIÑA 2) Ifigenia...comienza!

\section{ESCENA 9}

\section{Mujeres trágicas}

-Niña 2: (Ifigenia)

Bajo a la noche

soplo desesperadamente

soplo desesperadamente

las velas del barco de mi padre

mi aliento no tiene fuerza

soplo una y otra vez al amanecer

todos los hombres tendidos en la playa 
con su destino de guerreros quebrados

leo la mente de mi padre

desde niña leo la mente de mi padre

se debate en sí mismo le pide a Dios

aúlla como un lobo herido

como si me hubiera parido

le duelen las entrañas, sangra

-¡Detente!

(le digo)

y comienzo a odiarlo

los hombres bajan en la penumbra de la noche

a matar a otros hombres

-¡No quiero morir!

Dios tiene la sabiduría de la distancia

mira desde lejos

mi Dios tiene la sabiduría de la indiferencia

la incertidumbre de las palabras

palabras que jamás dicen nada

mar sinónimo de muerte

viento me falta el aire

fuego me arden las entrañas

amor entro en un espacio oscuro 
sombras, reflejos de una pira ardiendo

barco papel

dibujos que las tardes del domingo dormían en la servilleta

barco papel

papel cuadriculado del cuaderno de matemáticas

barquitos que navegaron en un charco sucio

en el que imaginé

maremoto tormenta suplica

digo barco y mi papel es el miedo

yo que soy menos que nada

¿he de entregarle el viento de la guerra a los hombres?

deseo el cuerpo de Aquiles tendido en la playa

pero la muerte me llegará desde fuera

sin probar el amor

quiero respirar ahora

soñar ahora

tener mañana ahora

mañana, mañana solo seré fuego...

leo la mente de mi padre

desde niña leo la mente de mi padre

y comienzo a odiarlo... 
(La NIÑA 1 y NIÑNA 3 aplauden. La NIÑA 2 saluda.)

-NIÑA 3: ¡Ahora tú!

(NIÑA 1 busca algún objeto en la maleta y comienza. Cassandra.)

-NIÑA 1: Lo que resuena en mi es lo que aprendo con mi cuerpo

la memoria me asalta como un estrépito incontenible

y surge plena de imágenes

que resuenan como ecos del pasado

como recuerdos del futuro

un futuro incierto por no sucedido

patético desolador

premonición inevitable

memoria de todas las muertes

la disolución del hombre

la visión

miles de hombres

envueltos en una nube de polvo

como humo que escapa

miles de huellas

borradas de la arena por un viento fuerte 
miles de ojos

enterrados por las tinieblas de un mar tormentoso

miles de gritos

apagados por la distancia de la historia

por la indiferencia del recuerdo

por la fragilidad de la memoria

¿un dios es un dios sin ser primero un hombre?

un dios es un hombre con más poder

más lujuria

más venganza

Apolo escupes mis labios

por negarte mi sexo

llevaré conmigo todo horror verdadero

la soledad de los hombres

los hará caer en la sangre

todo fue claro

la confusión de mi alma

los presagios, las muertes

encontraron su lugar y sentí

que me envolvía una paz definitiva

sólo un instante

el de perder el miedo 
sólo el instante de recoger

una gota salada en mis manos

y volver definitivamente

al dolor que guarda mi memoria

la vida siempre se viene encima

como una secuencia de errores

sufro con las alucinaciones del pasado

porque sé que se transformaran en futuro

Troya Irak Chile

todas las guerras

todas las muertes

todos los destierros

¿hay condena por escuchar al cuerpo?

el cuerpo es sagrado

solo su propio deseo puede desgarrarlo

mi voz es la voz de la mujer

que no ha sido creída

la ceguera de los hombres

me convierte en ciega muda

enredada entre la angustia y la pena

quería solo un instante

vivir la hermosa libertad 
de no saber lo que sé

por un instante

perder

la memoria la palabra el sentido

(La NIÑA 1 y NIÑA 3 aplauden con temor. La NIÑA 2 no saluda. La NIÑA 3 interrumpe con falso entusiasmo. Se viste mientras describe la situación.)

-NIÑA 3: Ahora yo, me toca a mí... (Suena una flauta. Ofelia.)

Oigo el murmullo del rio

En su voz tenue hay una llamada de auxilio

Estoy ahí para la muerte

Su voz se abre y se cierra como tus manos

El silencio del río es el silencio de la carretera

A la que me entregaría excitada y sedienta

Para no verte más Para no verme más

Para no verme morir Para no verte morir

El ruido del motor no es otro que el del agua

Veo tu sombra y mi reflejo

Y te siento Hamlet como siento el vacío

pesa el pelo las algas los troncos el musgo las piedras

Se quiebran las ramas de mis huesos 
Me convierto en branquias para darte luz y aire

Mi pequeño Hamlet tan pequeño que te llevo en mi vientre

El pelo mojado me arrastra hacia el fondo

Es un rio seco

No hay peces no hay flores ni frutos

no hay vida

Solo la semilla de mi vientre que viaja conmigo

Rio abajo entre las sombras

La sombra del castillo la sombra de mi padre la sombra del amor

No hay nada que decir

Solo tu voz encuentra eco en la eternidad

Tus palabras soberbias tu tono altanero ser o no ser

Mi garganta ya no tiene gritos

¿Qué es el grito de una mujer? ser o no ser

Silencio Silencio Silencio

Sobre las ondas del rio el suave silencio de tu nombre

Mi sombra desnuda un llanto eterno

La historia se repite como se repite el desamor

Me voy

tu corazón ya no dice nada nada nada

El amor es breve

tan leve que cualquier brisa lo levanta y lo pierde 
Mira las pequeñas ondas sobre las aguas del rio

Así de leve eres así de leve soy

Silencio Silencio nada nada nada

\section{ESCENA 10}

\section{La adolescencia}

La escena anterior rompe con la música Disco Infierno, las luces dan la idea de una discoteca ochentera. Las niñas van dejando en la maleta, el vestuario que habían cogido para sus personajes, mientras bailan y hablan.

-NIÑA 2: .... No te escucho

-NIÑA 3: Que lo vi...!

-NIÑA 2: ¿A quién?

-NIÑA 3: A Marc.

-NIÑA 2: ¿Marc?

-NIÑA 3: Lo vi, entrando en el bar

-NIÑA 2: $¿$ Y te vio?

-NIÑA 3: ¿Qué?

-NIÑA 2: ¿Qué si te vio él... a ti?

-NIÑA 3: No creo, iba con una chica... 
-NIÑA 2: Ella lo sabe

(Mirando a NIÑA 1.)

-NIÑA 3: ¿Qué?

-NIÑA 2: ¿Qué si lo sabe?

-NIÑA 3: No, no se lo he dicho

-NIÑA 2: Dile, dile, dile...

-NIÑA 3: No sé...

-NIÑA 2: Dile seguro que se pone verde...

-NIÑA 3: Hace tiempo que no dice nada de Marc...

-NIÑA 2: Hace tiempo que no dice nada de nada...

-NIÑA 3: Esta rara ¿no?

(NIÑA 1 se acerca bailando a NIÑA 2 y le habla. Indicando a NIÑA 3, que se acerca.)

-NIÑA 2: Lo vio, con una chica, entrando en un bar...

-NIÑA 1: ¿A quién?

-NIÑA 3: A Marc, lo vi entrando en un bar, iba con una chica...

-NIÑA 1: ¡Qué bien!

-NIÑA 3: Cómo que ¡qué bien!

-NIÑA 1: No me interesa 
-NIÑA 2: No te creo

-NIÑA 3: Pero si estabas colgada por él.

-NIÑA 1: Dije que no me interesa.

-NIÑA 3: No te creo

-NIÑA 1: Es un niñato, hace tiempo que no me interesa.

-NIÑA 3: Vamos, estás celosa...no me interesa já.!

-NIÑA 1: ¡No me interesa! ¡No me interesa! ÉL no me interesa. ¡Silencio!

Se apaga la luz y la música. Solo queda una luz sobre ella al centro de la escena.

\title{
ESCENA 11
}

\section{El profesor y la Alumna}

El abandono definitivo de la adolescencia.

\begin{abstract}
-ALUMNA: Lo había visto mirarme. Mirarme de esa manera, una forma paternalista y libidinosa. Lo había visto jugar con mi nombre como Humbert Humbet y saborear en su lengua esa pregunta tan estudiada que esperaba el momento para lanzar como un dardo. Una red de plata para atrapar a una sirena. Lo había presentido, pero no lo supe hasta después que todo se consumó.
\end{abstract}

(Dirigiéndose al PROFESOR.) 
-ALUMNA: ¿Qué dice Señor?

-PROFESOR: Mira hacia allá

-ALUMNA: ¿Qué'

-PROFESOR: Hacía la ventana, así, así de perfil

-ALUMNA: ¿Así?

-PROFESOR: Si, así.

-ALUMNA: $\ldots i ?$

-PROFESOR: ¿Te han dicho alguna vez que eres igual a la sirenita?

-ALUMNA: ¿Qué?

-PROFESOR: El perfil, el rostro.

-ALUMNA: ¿A quién? (Sonríe nerviosa)

-PROFESOR: A la sirenita.

-ALUMNA: No, Señor. ¿La sirenita? ¿Qué sirenita?

-PROFESOR: Si, la sirenita, la escultura que está en...

-ALUMNA: No le entiendo...

-PROFESOR: En Copenhagen hay una escultura de una sirena sentada sobre unas rocas, mirando el mar, es un homenaje a La Sirenita del cuento de Hans Christian Handersen.

-ALUMNA: No, no la he visto nunca...no sabía que existía. El cuento, de pequeña si, pero no... no recuerdo cómo...

-PROFESOR: Es una escultura hermosa. Tienes que verla, se parece mucho a ti.

-ALUMNA: ¿Si? 
-PROFESOR: Sí, la nariz, el rostro suave... (Le toca la cara.)

-ALUMNA: Yo...

-PROFESOR: Es muy bonita.

-ALUMNA: ¿Sí?

-PROFESOR: Vamos, yo te llevo, vamos a conocerla...

-ALUMNA: ¿A Dinamarca, Señor?

-PROFESOR: Sí, ¿te vienes conmigo?

-ALUMNA: ¿A Dinamarca?

-PROFESOR: O a hacer un café...un café primero, el bar está más cerca que Dinamarca. (Se ríe.)

-ALUMNA: ¿Iremos a Dinamarca?

-PROFESOR: Claro, si quieres después iremos a Dinamarca.

-ALUMNA: ¿Después?...

-PROFESOR: Claro, después del café.

-ALUMNA: Si, después del café...

-PROFESOR: ...Sirenita...

-ALUMNA: Me cogió del brazo. Y del café, pasamos al hotel. Y de la sirenita y Dinamarca a un cuarto sórdido y sucio del centro. Con las ventanas tapiadas y un colchón de agua... ¡Un colchón de agua!, donde la aventura del viaje y la dulzura se convirtieron en naufragio.

¡¿Qué no sabe que las sirenas no tienen sexo?! ¡Señor! ¡Cola de pez, cola de pez y nada más!!! Las sirenas no son penetradas, Señor. Con las sirenas no se puede, Señor. Las 
Sirenas no podemos, Señor. ¡Cola de pez, cola de pez y nada más, Señor!!! ¡Odio los colchones de agua!!! Y odio...odio las promesas...

\section{ESCENA 12}

\section{El Dolor}

Poema de Verlaine, Llueve suavemente sobre la ciudad (Il pleut doucement sur la ville) en castellano, francés y otros idiomas, con la música de Ravel, Pavana. Las voces se superponen como un tejido de lluvia. Los cuerpos caminan recorriendo el espacio en distintos ritmos, distintas direcciones, cruzando la rosa de los vientos, como sombras de otoño.

\section{-TODAS:}

Il pleure dans mi couer Llora mi corazón

Comme il pleut sur la ville. Como llueve en la ciudad.

Quelle est cette langueur ¿Qué languidez es ésta

Qui pénètre mon coeur? Que en mi corazón se ahonda?

On bruit doux la pluie $\quad$ ¡Murmullo suave de la lluvia

Par terre et sur les toits! En suelos y en tejados!

Pour un coeur qui s’ennuie, ¡En un corazón abatido

O le chant de la pluie! El canto de la lluvia! 
Il pleure sans raison $\quad$ ¡Ay, como llora sin motivo

Dans ce coeur qui s'écoeure En este corazón hastiado!

Quoi! Nulle trahison? ¿No hay traición alguna?

Ce deuil est sans raison. Este dolor es sin razón.

C'est bien la pire peine La peor de las penas

De ne savoir porquoi, Es ignorar por qué;

Sans amour et sans haine Mi corazón, sin odio y sin amor,

Mon couer a tant peine. $\quad$ está muy dolido.

\section{ESCENA 13}

\section{La Madurez}

-MUJER 1: Dejé a la orilla del río una pequeña barca de madera.

-MUJER 3: Que se fue llenando de hojas de otoño, ramas podridas, humedad, musgo...

-MUJER 2: Quedó ahí, atrapada entre dos piedras.

-MUJER 1: Cuando el agua del río bajó.

-MUJER 3: No era más que un viejo barco abandonado en la arena.

-MUJER 2: El río no estaba.

-MUJER 1: No, no había río...

-MUJER 3: Solo mástiles varados en la arena

-MUJER 2: Lo vi envejecer, robarle el agua, perecer de sequedad... 
-MUJER 1: Y vi las arrugas en el suelo, arrugas de arena...

-MUJER 3: Corrí a casa a mirarme, mirar los surcos del agua pasada. Pero mi imagen en el espejo me daba la espalda.

-MUJER 2: Era nuca, pelo, hombros, nada...

-MUJER 1: El espejo no me reconocía, no era yo.

-MUJER 3: Era otro yo, dándome la espalda

-MUJER 1: La última vez que me vi, llevaba un paño blanco en la cara y trataba de besarte, de besarme, de besar...

-MUJER 3: Y sobre las arenas del futuro las mujeres con los cantaros sobre sus cabezas dejando caer gotas aquí y allá sobre sus pieles secas.

-MUJER 2: ¿A dónde vas destino de pueblo seco?

-MUJER 3: Buscando una gota de agua y un beso.

-MUJER 1: Dime una historia.

-MUJER 3: Cojamos un punto en el mapa. De aquí o de allá...de allá y lo llamamos África. Por la noche sopla el viento y arrastra sobre la arena arbustos secos carcomidos por la arena.

Camina en puntas de pie dibujando el mapa. Suena un violín que imita al viento.

-MUJER 2: De día es un rodar de mujeres, cientos de mujeres con sus cantaros. Cántaros que no son de barro. Plásticos amarillos atados a la espalda para resguardar una gota de agua. Pies desnudos quemados por el sol, se arrastran, ruedan por la arena. 
-MUJER 1: ¿Dónde tiene África sus pozos de agua? ¿Dónde guardan ellas un beso?

Silencio.

\section{ESCENA 14}

\section{Acusación pública}

-PRESENTADOR: Buenas noches, noche...hoy vienen por el...para ganar...para saber...

Se mueren por millones se mueren

¿Cuántos millones? ¿Cuántos millones?

Qué importa cuántos millones millones de negros

¿Cuántas mujeres? Millones millones de mujeres negras

¿Cuántos niños muertos?

Millones de niños negros que jamás serán hombres negros

¿A ti te importa? ¿Y a ti? ¿Y a ti?

A los que están escuchando ¿les importa?

A los que miran ¿les importa?

A los que leen ¿les importa?

Pasan página al periódico y no saben ¿fueron cien?

¿O mil? ¿o un millón?

No importa qué importa son negros y quedan sepultados en la arena 
Cientos miles millones de granos de arena

Que alguna vez fueron hombres mujeres niños negros

No tiene que importarle a nadie. Eso es fundamental.

No tiene que importarle a nadie.

Así el mundo funciona Si a ti te importa o a mí me importa

La economía neo-liberal cae en picada

Lo importante es que no importe

Que nada más que tú y solo tú sea importante en este mundo

Tu comodidad tu lujo tus éxitos

Tus vacaciones tus reuniones tus amigos

Tus cenas tus cañas tus tapas

Lo importante es no compartir no compartir

En eso se basa la economía ¡No compartir!

Lo mío es mío solo mío

¿Dónde sustentamos nuestras creencias?

En el dinero en la comodidad en la seguridad

Fe en la seguridad

-PÚBLICO 1: Yo no tengo fe

-PRESENTADOR: ¿Qué?

-PÚBLICO 1: No tengo fe en nada ni en nadie

-PRESENTADOR: Pero, ¿cómo? 
-PÚBLICO 2: Yo habría recuperado la fe si el avión privado del Papa hubiese dado la vuelta

-PRESENTADOR: ¿Si hubiese dado la vuelta te habría devuelto la fe en el Papa?

-PÚBLICO 2: No, no en el Papa ni en la iglesia ni en Dios

Sino en un gesto humano Fe en el ser humano

-PÚBLICO 1: Si, en vez de venir a decirles a los niños pijos del mundo lo que no tiene que hacer... no sientan deseo... No se masturben No jueguen con su sexo No amen a quién quieran No sean libres no pueden ser libres La libertad es peligrosa

-PÚBLICO 2: Si ese individuo hubiese cogido su jet privado su séquito y todos sus millones y hubiese dirigido su avioncito a Somalia me habría devuelto la fe La fe en que al ser humano aún le queda un poco de humanidad

-PRESENTADOR: Bla, bla, bla, bla... ¿Y tú qué? ¿Qué haces tú por ellos? ¿Y tú? ¿Te importan? No, no te importa ni a ti ni a él ni él ni ella

En esta noche, noche, digamos la verdad A nadie le importa que millones de negros se mueran de hambre y de sed Que millones de negros se conviertan en arena blanca Solo queremos a los niños blancos que huyen del pecado y adoran al Papa a ellos sí que les damos todo Les damos toda el agua del mundo para que hagan más niños blancos obedientes de las leyes de Dios y del dinero Niños blancos que acumulen toneladas de dinero y que nos digan cómo vivir nuestra vida

-PÚBLICO 2: Tendría fe fe en el ser humano si alguno de ellos cogiera su avioncito y dejara caer su dinero convertido en agua sobre Somalia

-PÚBLICO 1: Lo mejor sería quedarse en silencio 
Todos los Políticos mudos

Todos los Banqueros mudos

Todos los Curas Papas Predicadores mudos

Todos mudos para no decir más mentiras

Y crear así una nueva raza humana

Una raza humana sin palabras sin mentiras sin promesas

Una raza humana silenciosa verdadera

Una raza humana muda

Una raza humana muda y verdadera

\section{ESCENA 15}

\section{EI Desierto}

Silencio desolador. Pausa. Se escucha el sonido del viento en el desierto.

-MUJER 1: ¿A qué me parezco?

-MUJER 2: Te pareces más a ese desierto temprano, al que acaba de abandonar el agua.

-MUJER 3: Al que tiene grietas como heridas y sangra piedras grises.

-MUJER 2: Al otro no, al antiguo. Al acostumbrado a la sequedad, ese se ha vuelto suave y melancólico, benevolente con el silencio y con la arena. 
-MUJER 1: Ese se deja quemar por la luz de la luna, y la sal de sus entrañas refleja caminos de agua imaginarios. Reflejos de luna en un mar de arena.

-MUJER 3: Tu no. Tú eres de sequedad reciente, las grietas te duelen intranquilas en el espejo. Y te niegas a dejar de beber dándole la espalda a la muerte como si la muerte tuviera rostro.

-MUJER 2: Tienes miedo y corres, corres con la mirada a miles de millas del espejo. Y tienes sed y corres tras una gota de agua

-MUJER 3: Y viene él y te la da, pero una solo. Solo una.

-MUJER 2: Y está ahí, el desierto está ahí, preparando su red. Un desierto lleno de peces como tu, antiguos como el miedo.

-MUJER 1: No más cabellos de oro o de carbón, no más ríos de agua turbulenta, no más deshielo sobre las piedras... solo huellas de plata en un mar de arena.

\section{ESCENA 16}

\section{Final. El ritual de la muerte}

Cuadro de los paraguas y el cadáver. Fauré: Andante de la Sonata no 1 para Cello.

-MUJER 3: No importa cuánta agua bebamos, siempre tendremos sed.

-MUJER 2: Sed de alma.

-MUJER 1: Sed de corazón. 
-MUJER 3: Sed de abrazos.

-MUJER 1: Somos hombres sedientos.

-MUJER 3: Sed de decir te quiero.

-MUJER 2: Sed de decir no te vayas.

-MUJER 1: Sed de decir me quedo.

-MUJER 3: Somos mujeres sedientas...

-MUJER 2: Sed de pertenecer o pertenecerte...

-MUJER 1: Estamos siempre a la orilla del muelle.

-MUJER 3: Donde los barcos se mecen golpeando la quilla.

-MUJER 1: Aplazando siempre el momento de partir.

-MUJER 2: Todos estamos sedientos...

-MUJER 3: Es el juego de las bocas.

-MUJER 1: Besos resecos de sal y palabras tontas.

-MUJER 3: Sonidos mezclados en el mar.

-MUJER 2: Y tus ojos y mis ojos.

-MUJER 1: Las lágrimas y el momento de partir....

-MUJER 2: No nos queda más que el momento de partir...

-MUJER 3: Solo sabemos que llegará el momento de partir...

-MUJER 2: Solo sabemos que llegará el momento de partir...

-MUJER 1: Solo sabemos que llegará el momento de partir...

-MUJER 3: Solo sabemos que llegará el momento de partir... Se escuchan 4 gotas de agua. 